\title{
Implementation of the Self-Directed Learning System in General Education Schools: Analysis of Manifestation of Changes
}

\author{
Ausra Kazlauskiene (Corresponding author) \\ Siauliai University, Visinskio St. 25, Siauliai, 76351-Lietuva \\ Tel: 370-6202-9614 E-mail: akazlauskiene@yahoo.com, akazlauskiene@ef.su.lt \\ Ramute Gaucaite \\ Siauliai University, Visinskio St. 25, Siauliai, 76351-Lietuva \\ Tel: 370-6999-2407 E-mail: ramuteg@yahoo.com, gaucaite@ef.su.lt \\ Rasa Poceviciene \\ Siauliai University, Visinskio St. 25, Siauliai, 76351-Lietuva \\ Tel: 370-6126-8406 E-mail: rasa.poceviciene@gmail.com
}

Received: November 1, 2014 Accepted: November 12, 2014 Published: December 8, 2014

doi:10.5296/jet.v2i1.6747ＵRL: http://dx.doi.org/10.5296/jet.v2i1.6747

\begin{abstract}
Currently particular emphasis is placed on adults' rather than children's self-directed learning. As to children's learning, it is dominated by episodic rather than systematic type of self-directed learning theory and practice. For a long time children as learners were undervalued, focusing more on the educator and on teaching techniques. Presenting the research on experience of implementing the self-directed (self-)education system, the authors of the article emphasise the importance of "liberal" learner-centred learning in childhood because namely then the foundations of learning management skills, which are based on a peculiar pace, goals, perspectives, style of learning, later determining adult learning culture too, are formed. Applying the method of semi-structured data collection, using reflective writing, manifestation of changes that took place implementing the (self-)education system was analysed.
\end{abstract}

Keywords: self-directed learning, changes in self-education 
Currently particular emphasis is placed on adults' rather than children's self-directed learning because the concept of lifelong learning culture is grounded namely on adult learning (Knowles, 1990).

Quite a number of experiences in the world demonstrate application of self-directed learning approach in the practice of adult learning (Knowles, 1970; Brookfield, 1984; Long et al., 1989; Merriam, 2001; Candy, 1991; Brockett, Hiemstra, 1991; Guglielmino \& Guglielmino, 2006; Merriam, Caffarella, \& Baumgartner, 2007).

As to children's learning, it is dominated by episodic rather than systematic type of self-directed learning theory and practice. For a long time children as learners were undervalued, focusing more on the educator and on teaching techniques. Considerably fewer researchers analysed various aspects of separate elements of general education school pupils' self-directed learning. Bolhuis and Voeten (2001); Martinez and McGrath (2013) performed deeper analysis of changes in educator roles, moving from what to teach to the paradigm how to teach. Spear (1984), Cooker (2010) analysed the influence of the environment on self-directed learning. In their researches Hout-Wolters, Simons, and Volet (2000) present two forms of active learning: self-directed learning and independent work. Nunan (2000) went deeper into organisation of self-directed learning for language teaching. Savery (2006), Thomas, Anderson, Nashon (2008) analysed problem-based learning, employing self-directed learning approaches. Zimmerman (1989) emphasised the importance of self-directed learning approach for social cognition. In his book Zimmerman (1989) described self-regulation models for learning and academic achievements.

Anyway, there is a lack of initiatives practically implementing both separate elements of children's self-directed learning and the whole self-directed learning system in the general education school. Researches on experience of implementing such system would particularly enrich the field of education. There is also a lack of studies describing manifestation of children's and adults' learning culture in various environments, the necessity of existence of these cultures as tantamount cultures, enabling to understand the multicultural phenomenon of lifelong learning. Based on this research, it will be sought to supplement the previously formulated problem areas with significant conclusions.

Creating the self-directed system of (self-)education, the authors of the article emphasise the importance of "liberal" learner-centred learning in childhood because namely then the foundations of learning management skills, which are based on a peculiar pace, goals, perspectives, style of learning, later determining adult learning culture too, are formed.

\section{Research Methodology}

Implementation of the self-directed system of (self-)education in five Lithuanian general education schools in 2010-2013 presupposed prerequisites that enabled investigation of self-directed teaching and learning practice through manifestation of changes in the process. The research was attended by 18 teachers in each school, who represented all subjects. Teachers, pupils, parents, social partners of schools were given methodical aids prepared in advance. In addition, throughout all academic year teachers took part in training workshops 
and consultations, implementing the acquired experience in their direct work. Training workshops were also organised for pupils and their parents. The project was followed by one of studies on manifestation of changes, which is presented in this article.

In order to make it easier to understand changes that have taken place in the organisation of pupils' learning in general education schools, we will concisely present key approaches of implementing the pupils' self-directed teaching and learning system (Kazlauskiene, Gaucaite, Masiliauskiene, \& Poceviciene, 2010, 2012):

- Implementing the self-directed teaching and learning system in general education schools, the focus was on management of constructing new knowledge of the learner, which manifests itself through (self-)education of the learner who is able to employ new knowledge in order to understand ongoing socio-cultural phenomena, mastering self-learning, self-development, self-knowledge competencies (which also mean value-based and culture-based knowledge creation). During the (self-)education process the learner is treated as the participant of management of knowledge creation, constructing knowledge corresponding to the modern society, and the teacher, managing learning processes, with reason involves the learner into knowledge construction because then the learner understands value-based meanings of knowledge construction.

- In the context of individualization of the learning process self-directed learning is actualised, involving such activities of the learner which are characterized by his/her own ability to organise, manage, monitor and assess his/her own learning process, i.e., independently set learning goals, plan the learning process (steps) and implement it, find necessary information, solve learning problems and reflect on the learning process.

- Changes in implementation of the self-directed learning system in general education schools were actualized through changes in educators and pupils as persons and through changes in the teaching and learning process.

\subsection{Research Method}

In order to find out manifestation of changes that took place during implementation of the system, the semi-structured data collection method, employing written reflections, was used. The choice of such method was influenced by compliance with the approach that changes in teaching and learning activities and otherness of those activities were represented by reflections of the teachers involved in activities related to implementation of the system. It should also be emphasized that in Lithuania no class had organised self-directed learning before the beginning of implementation of the said system.

Teachers had to answer open-ended questions. The volume of the textual part was not limited. Data were analyzed following the logic of understanding and interpretation of the whole of written reflections and of its parts, using the qualitative research software "Kokybis" (2013). This way it was sought to understand the full text in general, which enables subsequent evaluation of different parts of the given text, identification of main categories, which are the basis of constructed meaning (Lindseth \& Norberg, 2004). 


\subsection{Organisation of the Research}

The plan of research organisation projected reaching as high as possible degree of representativeness, which is one of the measures of quality of the social research. Based on the conditionally named arguments listed below, it can be stated that sufficiently high degree of representativeness was reached in the research on manifestation of changes that took place implementing the self-directed teaching and learning system.

- Territorial representativeness: the research was attended by five schools who took part in the implementation of the innovative educational system. In these schools teachers represented all subjects taught in 5-8 forms.

- Institutional representativeness: the research was attended by not less than 90 per cent of teachers $(\mathrm{N}=90)$ who took part in the implementation of the self-directed teaching and learning system in the general education school.

\section{Analysis of the Research}

\subsection{Analysis of Manifestation of Changes after Implementation of the Self-Directed Teaching and Learning System}

Having generalised research results, it can be stated that three main blocks contextualising changes can be distinguished (change in the person of the teacher, change in the learning process, and change that has not taken place) (see Table 1).

Table 1. Changes in teachers' activities, implementing the self-directed learning system

\begin{tabular}{|c|c|}
\hline Topic & Illustrating arguments \\
\hline \multirow{5}{*}{$\begin{array}{l}\text { Change in the person of the } \\
\text { teacher }\end{array}$} & Acquired new knowledge, learned new technologies \\
\hline & The teacher's attitude to learning has changed \\
\hline & The teacher's attitude to the pupil as a self-directed learner has changed \\
\hline & Personal traits have changed \\
\hline & $\begin{array}{l}\text { The teacher started paying more attention to self-assessment of his/her } \\
\text { activity }\end{array}$ \\
\hline \multirow{9}{*}{$\begin{array}{l}\text { Change in the teaching and } \\
\text { learning process }\end{array}$} & Started setting different goals or setting goals in a different way. \\
\hline & $\begin{array}{l}\text { Started planning the teaching process and children's learning process } \\
\text { differently }\end{array}$ \\
\hline & Started applying different self-assessment of the pupil's abilities \\
\hline & Different questions and changes in questioning \\
\hline & Started using a larger number of more diverse methods \\
\hline & Promoted pupils' independence \\
\hline & Organise teaching and learning according to the style \\
\hline & Organise learning according to the child's experience and abilities \\
\hline & $\begin{array}{l}\text { Paid attention to the essence of self-motivation and promoted learning } \\
\text { motivation }\end{array}$ \\
\hline Change did not take place & $\begin{array}{l}\text { Part of educators think that they had worked this way before the } \\
\text { beginning of implementation of the said system. }\end{array}$ \\
\hline
\end{tabular}


Changes did not take place. Consequences and changes during implementation of the self-directed learning system did not take place or were unnoticeable because part of educators thought that they had worked this way already before the beginning of implementation of the said system:

- "Because I am permanently learning and improving my qualification, I can state that my teaching namely due to the project has not changed; I don't think that it has changed. It verified that I had been working this way for a number of years".

- "Did not change".

Such manifestation of changes could have been determined by initial approach of teachers who took part in implementation of the self-directed teaching and learning system, when the teacher treated himself/herself as the main participant of the teaching and learning organisation process, focusing on the subject and its results. It is likely that part of educators remained faithful to their previous attitude and opinion about organisation of the teaching and learning process even after implementation of the system. This is illustrated by short answers with no reflection that organisation of teaching has not changed.

On the other hand, the fact that a share of teachers state that changes did not take place, enables to assume that implementation of self-directed teaching and learning at school, like every novelty, received resistance and that it is a certain challenge both for separate teachers and for the school as the institution.

\subsection{Change in the Person of the Teacher}

Training workshops and trying out of practical tasks, which took place during implementation of the self-directed teaching and learning system in general education schools, presupposed changes in the very teacher as a personality and in his/her attitudes. These are changes that take place in the most difficult way but most probably are most important with regard to changes in activities: the person acts the way he or she thinks. The analysis of reflections disclose changes in teachers' attitude to the pupil, they started trusting the pupil as a learner more:

- "First I started trusting pupils more, having organised work properly, they can learn on their own too";

- "Relations with pupils have slightly changed: there is more collaboration, discussions, pupils felt more responsible for their learning results, learned to assess and self-evaluate".

While the attitude to the pupil as a self-directed learner was changing, the teacher's personal traits were changing too:

- "I became braver letting not only strong pupils work in a self-directed way".

It should be noticed that the teacher, organising the pupil's activity, focuses not on himself/herself but on the pupil, acknowledging his/her personal traits and experience as values significant for learning: 
- 'I pay more attention to pupils' cognition, organisation of pupils' activity in the lesson, etc. Earlier I might have paid more attention to how I would like to conduct the lesson".

Training workshops and consultations, which took place during the implementation of the self-directed teaching and learning system supplemented teachers' knowledge baggage, enabled them to participate in creation of their own awareness, while practical sessions helped to deepen their practical skills. Changes that took place undoubtedly changed attitude to learning and its organisation: this facilitated to gradually transfer to organisation of self-directed learning and replace traditional teaching with self-directed learning:

- "I had heard about almost all methods and tried out part of them but when I started to take part in the project and more often thought and spoke about self-directed teaching and learning, quite naturally I started using self-directed teaching methods and giving adjusted tasks more often. Not everything was and is successful but part of pupils find such teaching and learning principle suitable";

- "Before the project traditional teaching dominated, now I am trying to replace it with experiential”.

It is important to notice that educators reflect on their activities and that failures do not stop them because they see that part of pupils find such teaching really suitable.

Because self-directed learning and its organisation at school is a new phenomenon of the educational practice, the teacher's new experience inevitably provokes to discuss and consider what is happening with him/her and his/her learners; i.e., to reflect on his/her activity:

- "I started paying more attention to reflection, how I work, whether I "feed pupils with the spoon" or they work on their own. I observe pupils whether they are dependent or self-directed and jot down all of it in my notes".

To sum up the spectrum of changes related to the teacher's personality, it can be concluded that implementation of the self-directed teaching and learning system enabled the teacher to express himself/herself as a self-directed learner, change and develop his/her own personal learning management experience.

\subsection{Change in the Learning Process}

Change in the teacher's attitude to learning as a phenomenon, to the pupil and his/her activity and his/her own activity at school influences change in the organisation of children's learning: this ensures transfer from the teaching paradigm to the learning paradigm. Based on teachers' reflections, change in the learning process, manifesting itself through change in the very teacher's and pupils' actions and activities, show up. The most distinct change in the teacher's activity is that the teacher makes every effort to promote the pupil's independence and support his/her initiatives:

- "I think up more tasks for self-studying";

- "I often let pupils choose topics themselves if these topics correspond to the goals of the lesson". 
One of the key endeavours of self-directed learning is to encourage pupil's independence while he/she is learning in every possible way. This way the teacher's responsibility gives way to the pupil's responsibility and the pupil becomes an active participant of his/her learning process, dependence on the teacher is reduced:

- "The pupil becomes an active participant of the teaching and learning process, who is responsible for his/her learning. The pupil's dependence on the teacher becomes much less".

When pupils' learning is organised as self-directed learning, the teacher becomes a facilitator of the pupil's learning:

- "Pupils are provided with favourable environment during lessons to disclose their experience, which is the basis for creation of new awareness and enables pupils to teach each other and present individual experience".

One of the conditions promoting the pupil's independence is that the teacher should organise pupils' learning, considering the pupil's individual experience and potential, and use them as a basis for the teaching and learning process:

- "Pupils are provided with favourable environment during lessons to disclose their experience, which is the basis for creation of new awareness and enables pupils to teach each other and present individual experience";

- "I differentiate tasks according to the child's abilities".

The use of children's experiences and potential for their learning management inevitably necessitates creation of conditions for the pupil to learn in such manner which is most suitable only for that pupil: setting of the most suitable learning strategy according to the pupil's characteristic learning style. Reflecting on changes which appeared as a result of the project, teachers expressed this dimension sufficiently distinctly:

- $\quad$ "During class meetings we performed several tests to identify learning styles. Together with pupils we analysed how to choose the best learning strategy according to the tests";

- "I focus more on diversity of pupils'learning, I consider learning types".

To be able to teach pupils to be self-directed, it is not sufficient to follow traditional methods, more diverse methods that are more suitable for children's individual learning have to be chosen. During the implementation of the system teachers were offered diverse learning methods, and their usage is also expressed in teachers' reflections:

- "In the lesson I used more diverse methods, I learned to use more diverse computer software, acquired new psychological knowledge".

The research also disclosed the teacher's efforts to promote pupils' analytical thinking, giving open type questions:

- "I am trying to give questions "Why? How?" more often in the lesson. 
The teacher's released self-confidence and trust in pupils enabled manifestation of pupils' potential that is related to learning to manage one's learning. Teachers' reflections revealed pupils' increased potential to set goals, seek implementation of the goal by planning activities, self-evaluate their knowledge and find out what still needs to be learned, etc., which improved the current situation:

- $\quad$ "First, this improved setting lesson goals. Splitting up of the goal enables pupils to self-evaluate their knowledge and achievements";

- "Facilitated setting lesson goals and tasks. Pupils find it easier to self-evaluate their knowledge and achievements";

- "Improved setting lesson goals, splitting up of the goal enabled pupils to plan their learning in the lesson, self-evaluating their knowledge and achievements, foreseeing what still can be learned".

In summary, it can be assumed that implementation of the self-directed learning system at school changed both the teacher's and the student's activities. To ensure that these changes take place, it is important that the personality of the very teacher should change - this is one of the main factors of implementing the self-directed learning system at school. Perception of the teacher's (self-)educational process determines how much he/she will allow pupils to be self-directed, how much such teacher will be determined and willing to share responsibilities with pupils, their parents, etc.

\subsection{Analysis of Concrete Features that Demonstrate Change in the Teaching and Learning Process}

To collect concrete features that show change in the teaching and learning process, teachers' opinion purifying them was analysed (Table 2).

Table 2. Features that enabled teachers to understand that their teaching has changed

\begin{tabular}{|c|c|c|}
\hline & Topics & Illustrating statements \\
\hline \multirow{3}{*}{$\begin{array}{c}\text { Features of } \\
\text { change are not } \\
\text { expressed } \\
\end{array}$} & & Has not changed \\
\hline & & Change is indistinct \\
\hline & & Cannot name features \\
\hline \multirow{11}{*}{$\begin{array}{l}\text { Expressed } \\
\text { features of } \\
\text { change }\end{array}$} & \multirow{4}{*}{$\begin{array}{l}\text { Change in the } \\
\text { organisation of the } \\
\text { educational } \\
\text { process }\end{array}$} & By differentiation of the educational process \\
\hline & & By applied methods \\
\hline & & Preparation for the work process requires more efforts \\
\hline & & Change in the type of activity in the lesson \\
\hline & \multirow[b]{2}{*}{$\begin{array}{l}\text { Change in the } \\
\text { teacher's activity }\end{array}$} & By changes in the teacher's roles \\
\hline & & $\begin{array}{l}\text { By the attitude to the perspective of applying this } \\
\text { system }\end{array}$ \\
\hline & \multirow{5}{*}{$\begin{array}{l}\text { Change in the } \\
\text { pupil's activity } \\
\text { and attitude }\end{array}$} & Pupils' independence has increased \\
\hline & & Collaborate more \\
\hline & & Change in pupils' reaction \\
\hline & & Motivation has changed \\
\hline & & Interest has increased \\
\hline
\end{tabular}


Features of the change are not expressed. Changes in the teaching and learning process organised by teachers who took part in implementation of self-directed learning are witnessed by various features, which vary encompassing both activities of subjects of education and organisation of the self-educational process. This is in principal confirmed by teachers' expressed and analysed tendencies of change (Table 1). It was also verified that such features were not found in the activities of part of teachers or they were not distinctly expressed. There were cases when teachers could not name concrete features.

Expressed features of change are described in three fields: change in the organisation of the educational process; change in the teacher's activity; change in the pupil's activity and attitude.

\subsection{Change in the Organisation of the Educational Process}

Different way of teaching in the classroom was noticed by teachers who took part in the implementation of the system, who stated that the same teaching and learning for all was no longer suitable and that they more often differentiated the educational process:

- "I pay more attention to differentiation of the educational process";

Differentiation of the educational process is accompanied by diversity of methods, manifestation of which can also indicate ongoing changes. Such teaching also changed the very teacher's approach to some of the methods used, which they thought to be ineffective:

- "During the lesson with several classes I have to use new methods that I earlier treated as inefficient ".

It can be assumed that "efficiency of the method" showed up when the teacher perceived the essence of self-directed learning that pupils' activities, which at first glance seemed as "games" (this is how teachers named many methods during practical training), were significant when the child was learning to manage his/her learning, promoting his/her interest in learning activities, etc. This has also influenced change in the type of activity in the lesson.

Reflecting on change in their activities, teachers also highlighted externally noticeable features related to increased efforts and time input to prepare for implementation of this kind of activity. Typically, the increase in efforts and time input are treated as a negative phenomenon. However, in this case teachers notice that the changed process, pupils' learning motivation and attractiveness of activities pay back:

- "Work process has lengthened but pupils find it more interesting, they willingly grasp novelties";

- "Preparation for the lesson lengthened and work in the lesson is more mobile".

\subsection{Change in the Teacher's Activity}

Changes in pupils' and the very teacher's activities organised until now require efforts and time. In their reflections teachers state that their role in the classroom has changed ("I act more as an advisor, guide; children work more, explain themselves”). This enables to think 
that the teacher turns into a supporter, adviser and not a direct conveyer of knowledge, who takes responsibility for the child's learning and mastering. Of course responsibilities do not disappear anywhere, they are redistributed passing part of them to the pupil because in this case the very pupil becomes the most important subject of (self-)education. This in principal corresponds to the learning paradigm and would be a good way and a good system, enabling to implement essential approaches of the learning paradigm in the (self-)educational practice.

\subsection{Change in the Pupil's Activity and Attitude}

Manifestation of otherness of teaching and learning is represented by changes in pupils' activity, which were recorded by teachers in their reflections. They noticed pupils' increased independence and activeness:

- "Frequently given questions";

- "Pupils take part in goal setting and goal splitting (have to/want to learn, already know, still have to learn). Some are able to set a plan how they are going to seek that goal, create tasks".

Such processes provoke organisation of the teaching and learning process grounded on collaboration strategy. Pupils' activity encompassed an increased need to collaborate with other children, work in a team and seek joint results, maintaining the importance of one's input:

- "During the larger part of the lesson pupils work on their own, collaborate, assess their own and other pupils 'performed tasks";

- "Teaching and learning became grounded on collaboration, pupils are more positive towards learning”.

Teamwork enables pupils to exchange experiences, position themselves, feel important members of the group, while learning becomes more attractive, cheerful and this motivates pupils. As concrete evidences, teachers indicate namely change in pupils' motivation and different attitude to learning.

Change in motivation is also shown by increase of children's interest in what is going on here and now in the classroom, they do various assignments more willingly:

- "Pupils do some tasks with greater interest";

- $\quad$ "Work process has lengthened but it is more interesting for pupils, they willingly grasp novelties."

Active interest influences mastering of information, resulting in children's higher receptivity, information acquisition becomes deeper and long-term.

Due to changes in the roles of the teacher and pupils, redistribution of limits of responsibility, teachers also indicate another feature: both positive and negative reaction of pupils because not all of them are "satisfied" with such changes which presuppose that pupils have to make more efforts and spare more time for learning, work more, there is no one to blame for 
undone homework, etc. This can be treated as barriers, which aggravate the teacher's activity and overcoming of which requires additional efforts.

\section{Conclusions}

The analysis of reflections on impact of implementation of the self-directed learning and teaching system on the teacher's activity results in sufficiently diverse experiences, encompassing change in teachers' activities, ranging from complete absence of change in the teacher's activities or unnoticeable changes to positive change in separate elements of the teaching and learning process and in holistic organization of self-directed learning and teaching, the main axis of which is the change in the teacher's culture, represented by change in the attitude towards the pupil and change in the organisation of the self-directed learning process. One of the most important factors of "otherness" of organising teaching and learning is change in the very teacher's culture (his/her attitude to the pupil, teaching and learning, etc.). External factors are positioned as secondary, not attaching such significance to them, which was characteristic at the beginning of implementation of the system.

Complete absence of changes in the teacher's activity or unnoticeable changes enable to assume that the self-directed teaching and learning system in Lithuanian general education schools is treated as educational innovation. It's implementation, like every innovation, receives (and will receive in the future) certain resistance and this is to be treated as a certain challenge both for separate teachers and for the school as an institution.

Teachers treat the pupil's preparation and ability to be self-directed as the initial factor governing success and as a purpose, result of self-directed learning. This suggests that in teachers' conception the system of self-directed learning is not fully perceived and requires deeper consolidation, tested in the practical activity.

Summarizing research results, it can be assumed that implementation of the self-directed learning system at school has changed the activities of both teachers and pupils. To ensure that these changes take place, it is important that the personality of the very teacher should change - this is one of the main factors of implementing the self-directed learning system at school. Perception of the teacher's (self-)educational process determines how much he/she will allow pupils to be self-directed, how much such teacher will be determined and willing to share responsibilities with pupils, their parents, etc. To sum up the spectrum of changes related to the teacher's personality, it can be assumed that implementation of the self-directed teaching and teaching system has enabled the teacher to express himself/herself as a self-directed learner, change and develop his/her own personal experience of managing learning.

\section{References}

Bitinas, B., Kazlauskienè, A., \& Jazgevicius, A. (2013). The open-source program for qualitative research „Kokybis“. Siauliai, Siauliai University Press.

Bolhuis, S., \& Voeten, M. J. (2001). Toward self-directed learning in secondary schools: what do teachers do? Teaching and Teacher Education, 17(7), 837-855. http://dx.doi.org/10.1016/ 
S0742-051X(01)00034-8

Brockett, R. G., \& Hiemstra, R. (1991). Self-Direction in Adult Learning: Perspectives on Theory, Research, and Practice. Routledge Series on Theory and Practice of Adult Education in North America. New York: Routledge, Chapman and Hall.

Brookfield, S. (1984). Self-Directed Adult Learning: A Critical Paradigm. Adult Education Quarterl, 35(2), 59-71. http://dx.doi.org/10.1177/0001848184035002001.

Candy, Ph. C. (1991). Self-Direction for Lifelong Learning. A Comprehensive Guide to Theory and Practice. San Francisco: Jossey-Bass Publishers.

Cooker, L. (2010). Some self-access principles. Studies in Self-Access Learning Journal, 1(1), 5-9. Retrieved November 18, 2014, from http://sisaljournal.org/archives/jun10/cooker/

Gaucaite, R., Masiliauskiene, E., Kazlauskiene, A., \& Poceviciene, R. (2012). Self-Directed Learning - Learning or Life: Abstracts of Book Series for Pupils Teachers, Parents. Teacher Education, 18(1), 123-130. Retrieved November 18, 2014, from http://vddb.library.lt/ fedora/get/LT-eLABa-0001:J.04 2012 ISSN_1822-119X.N_18_1.PG_123-129/DS.002.0.01. ARTIC

Guglielmino, P. J., \& Guglielmino, L. M. (2006). Culture, Self-Directed Learning Readiness, and Per Capita Income in Five Countries. SAM Advanced Management Journal, Spring, 21-28. Retrieved November 18, 2014, from http://org8220renner.alliant.wikispaces.net/file/ view/Guglielmino.pdf

Kazlauskiene, A., Masiliauskiene, E., Gaucaite, R., \& Poceviciene, R. (2010). Organisation of Self-Directed Learning as Educational Innovation: the Context of the Bologna Process. Teacher Education, 15(2), 95-111. Retrieved November 18, http://vddb.library.lt/ fedora/get/LT-eLABa-0001:J.04 2010 ISSN_1822-119X.N_15_2.PG_95-111/DS.002.0.01.

ARTIC

Knowles, M. (1970). Modern practice of adult education. Cambrige Adult education. Prentice Hall Regents, Englewoods Cliffs, NJ.

Lindseth, A., \& Norberg, A. (2004). A phenomenological hermeneutical method for researching lived experience. Scandinavian Journal of Caring Sciences, 18, 145-153. http://dx.doi.org/10.1111/j.1471-6712.2004.00258.x

Long, H. B. (1989). Self-Directed Learning: Emerging Theory \& Practice. Oklahoma Research Center for Continuing Professional and Higher Education, McCarter Hall, University of Oklahoma, Norman, OK.

Martinez, M. R., \& McGrath, D. (2013). How Can Schools Develop Self-Directed Learners? Phi Delta Kappan, 95(2), 23-27. http://dx.doi.org/10.1177/003172171309500206

Merriam, Sh. B. (2001). Andragogy and Self-Directed Learning: Pillars of Adult Learning Theory. New Directions for Adult and Continuing Education, 89, 3-14. http://dx.doi.org/ $10.1002 /$ ace. 3 
Merriam, Sh. B., Caffarella, M. S., \& Baumgartner, L. M. (2007). Learning in adulthood - A Comprehensive Guide. John Wiley\&Sons, Inc.

Nunan, D. (2000). The self-directed teacher: managing the learning process. Cambridge University press.

Savery, J. R. (2006). Overview of Problem-based Learning: Definitions and Distinctions. Interdisciplinary Journal of Problem-based Learning, 1(1), 9-20. http://dx.doi.org/10.7771/ 1541-5015.1002

Spear, G. E. (1984). The Organizing Circumstance: Environmental Determinants in Self-Directed Learning. Adult Education Quarterly, 35(1), 1-10. http://dx.doi.org/10.1177/ 0001848184035001001

Thomas, G. P., Anderson, D., \& Nashon, S. (2008). Development of an instrument designed to investigate elements of science students' metacognition, self-efficacy and learning processes: the SEMLI-S. International Journal of Science Education, 30, 1701-1724. http://dx.doi.org/10.1080/09500690701482493

van Hout-Wolters, B., Simons, R. J., \& Volet S. (2000). Active Learning: Self-directed Learning and Independent Work. In R. J. Simons, J. van der Linden, T. Duffy (Eds.), New Learning (pp. 21-36).

Zimmerman, B. J. (1989). A social cognitive view of self-regulated academic learning. Journal of Educational Psychology, 81(3), 329-339. http://dx.doi.org/10.1037/0022-0663.81. 3.329

Zimmerman, B. J. (1989). Models of Self-Regulated Learning and Academic Achievement. New York: Springer.

\section{Copyright Disclaimer}

Copyright reserved by the author(s).

This article is an open-access article distributed under the terms and conditions of the Creative Commons Attribution license (http://creativecommons.org/licenses/by/3.0/). 